

\title{
VI - Os órgãos públicos e as políticas de ocupação e valorização da Amazônia
}

\author{
Fernando Henrique Cardoso \\ Geraldo Müller
}

SciELO Books / SciELO Livros / SciELO Libros

CARDOSO, FH., and MÜLLER, G. Amazônia: expansão do capitalismo [online]. Rio de Janeiro: Centro Edelstein de Pesquisas Sociais, 2008. pp. 84-109. Os órgãos públicos e as políticas de ocupação e valorização da Amazônia. ISBN: 978-85-99662-73-1. Available from SciELO Books $<$ http://books.scielo.org $>$.

\section{(1) $(0$}

All the contents of this chapter, except where otherwise noted, is licensed under a Creative Commons Attribution-Non Commercial-ShareAlike 3.0 Unported.

Todo o conteúdo deste capítulo, exceto quando houver ressalva, é publicado sob a licença Creative Commons Atribuição Uso Não Comercial - Partilha nos Mesmos Termos 3.0 Não adaptada.

Todo el contenido de este capítulo, excepto donde se indique lo contrario, está bajo licencia de la licencia Creative Commons Reconocimento-NoComercial-CompartirIgual 3.0 Unported. 


\section{VI - Os órgãos públicos e as políticas de ocupação e valorização da Amazônia}

Este capítulo e o seguinte esboçam a evolução da política governamental em relação à Amazônia no que respeita à sua ocupação e valorização, que criou condições para o capital privado atuar naquele espaço brasileiro. Enfatizam-se as estruturas jurídico-administrativas dos principais órgãos e mecanismos estatais; incursiona-se resumidamente na metodologia utilizada pela SUDAM e pelo INCRA - lançando mão dos exemplos de Altamira e Marabá - para o encaminhamento da ocupação do solo.

O primeiro passo importante para a implantação de uma política de desenvolvimento e integração da Amazônia ao resto do país foi dado durante a Constituinte de 1946 quando, por iniciativa de parlamentares da região, foi aprovado e incluído na Nova Constituição o artigo nº.199:

Na execução do Plano de Valorização Econômica da Amazônia, a União aplicará, durante, pelo menos, vinte anos consecutivos, quantia não inferior a três por cento de sua renda tributária.

Parágrafo único: Os Estados e os Territórios daquela região, bem como os respectivos Municípios, reservarão, para o mesmo fim, anualmente, três por cento de suas rendas tributárias. Os recursos de que trata este parágrafo serão aplicados por intermédio do Governo Federal.

Em 1953, Getúlio Vargas sancionou a Lei $n^{\circ}$. 1.806, que definia como objetivos principais do Plano os que seguem:

- promover o desenvolvimento da produção agrícola, extrativa e animal, tendo em vista o aumento da produtividade do trabalho e a elevação do nível de vida da população da região;

- recuperar e tomar aproveitáveis as áreas inundáveis; explorar os recursos minerais da região;

- favorecer a industrialização de matérias-primas nativas para o mercado interno e a exportação dos produtos naturais;

- elaborar e executar um plano de transportes e comunicações para a Amazônia; 
- promover o estabelecimento de uma política de energia, através da utilização racional dos recursos naturais, para o fornecimento aos principais centros de produção e da indústria;

- interessar o capital privado na exploração das riquezas regionais, inclusive em empreendimentos de capital misto;

- estabelecer uma política demográfica que compreenda a regeneração física e social das populações da região, pela alimentação, a assistência à saúde, o saneamento, a educação e o ensino, a imigração de correntes de população que mais convenham aos interesses da região e do país, e o agrupamento dos elementos humanos da região ou de outros Estados em áreas escolhidas, onde possam constituir núcleos rurais permanentes e desenvolver a produção econômica;

- criar um sistema de crédito bancário regional;

- promover pesquisas (geográficas, naturais, tecnológicas e sociais) necessárias à elaboração e execução do Plano, recrutando e preparando pessoal especializado nos problemas da região;

- manter um serviço de divulgação econômica e comercial, visando ao conhecimento total das possibilidades econômicas da área, mantendo inclusive representações nos principais centros do país;

- orientar a organização administrativa necessária ao controle e execução do Plano, estabelecendo a coordenação entre os órgãos federais entre si e com os governos estaduais e municipais.

\section{A Superintendência do Plano de Valorização da Amazônia (SPVEA)}

Para a execução desse Plano foi criada a SPVEA, com autonomia administrativa e subordinação direta à Presidência da República. A Superintendência tinha como funções básicas a elaboração quinquenal do Plano - que devia ser apresentado ao Congresso Nacional para aprovação e o controle de sua execução. Dispunha também de poderes suficientes para coordenar, a nível nacional, as atividades de todos os órgãos que atuassem na região amazônica, impondo diretrizes e modificando programas conforme as prioridades que estabelecesse, ficando a seu cargo, inclusive, a distribuição das verbas destinadas a muitos desses órgãos.
A SPVEA contava com um superintendente que presidia também a Comissão de Planejamento da Valorização Econômica da Amazônia (art. 24 da Lei $n^{\circ}$. 1.806). Esta comissão era composta de quinze membros (seis técnicos, um para cada setor geral do Plano, e nove representantes dos Estados e Territórios localizados na região) e tinha suas funções reguladas pelo poder executivo. Suas atribuições principais consistiam em (art. 25):

- elaborar os planejamentos quinquenais que compunham Plano e enviá-los ao Presidente da República;

- alterar e rever o Plano;

- fazer a proposta anual do orçamento geral.

Juntamente com. a Superintendência foi criado o Fundo de Valorização Econômica da Amazônia (art. $8^{\circ}$. da Lei n ${ }^{\circ}$. 1.806), encarregado de custear a execução do Plano. Este Fundo se compunha de (art. $5^{\circ}$ do decreto $\mathrm{n}^{\circ}$. 34.132):

$-3 \%$ da renda tributária da União;

- 3\% da renda tributária dos Estados, Territórios e Municípios localizados na região amazônica;

- o produto das operações de crédito e de dotações extraordinárias da União, dos Estados, Territórios e Municípios, assim como das rendas provenientes dos serviços prestados pelo Plano;

- os juros dos depósitos bancários efetuados com os recursos do Fundo;

- os saldos dos balanços anuais do Plano.

Todos esses recursos eram obrigatoriamente depositados no Banco do Brasil, só podendo ser sacados pelo Superintendente da SPVEA.

Em 1966 houve uma redefinição dos objetivos principais do Plano, juntamente com outras modificações fundamentais que abordaremos mais adiante.

As novas diretrizes estabeleceram o Plano de Valorização Econômica da Amazônia (Lei nº. 5.173, de 27 de outubro de 1966: art. $4^{\circ}$ ). O Plano dispunha que: 
- as atividades na região seriam fundamentadas em pesquisas e levantamentos efetuados sobre seu potencial econômico;

- dever-se-ia proceder à seleção de espaços econômicos mais propícios ao desenvolvimento, onde pudessem estabelecer-se pólos de crescimento cujos efeitos se irradiassem por uma área maior;

- dever-se-ia aplicar maior soma de recursos em áreas selecionadas segundo as possibilidades de desenvolvimento e a população já existente;

- dever-se-ia visar à "formação de grupos populacionais estáveis, tendente a um processo de autossustentação"; buscar-se-ia a "adoção de política imigratória para a região, com aproveitamento de excedentes populacionais internos e contingentes selecionados externos";

- visava-se à "fixação de populações regionais, especialmente no que concerne às zonas de fronteira";

- deveria existir maior organização no aproveitamento dos recursos naturais da região, mas somente incentivando a economia extrativista quando esta não pudesse ser substituída por atividade mais rentável;

- dever-se-ia incentivar o desenvolvimento da agricultura, pecuária e piscicultura como fontes básicas de sustento das populações regionais;

- seria necessário especializar e qualificar a mão de obra para o desenvolvimento da região;

- far-se-ia a aplicação conjunta de todas as verbas federais, assim como das provenientes do setor privado e de fontes externas;

- seria propiciada a criação de uma política de incentivos fiscais e creditícios, visando a incentivar os investidores nacionais e estrangeiros a realizar empreendimentos na região e nela reinverter os lucros obtidos; dever-se-iam resguardar para a iniciativa privada as atividades econômicas rentáveis (industriais, agrícolas, pecuárias, comerciais e de serviços básicos), ficando a parte de infraestrutura, planejamento e pesquisa com o governo; Amazônia.
Como se pode perceber, houve algumas modificações importantes nas diretrizes básicas estabelecidas para o primeiro Plano - elaborado em 1953 - e este último, de 1966. O primeiro propunha-se tarefas de difícil realização, exceto a prazos muito longos e que requeriam um conhecimento da região muito maior do que se dispunha na época. Recuperar e tornar economicamente aproveitáveis as áreas inundáveis, explorar os recursos minerais da região (sobre os quais somente agora se têm melhores informações), implantar uma rede de comunicações e transporte (o que começou a ser realizado a custos muito altos, dado o desconhecimento da topografia da região), tais eram alguns dos objetivos do primeiro Plano que não figuram no segundo. Isto não significa que o governo tenha simplesmente abandonado estes setores, mas que houve uma mudança tanto na ênfase com que foram definidos os novos objetivos quanto na maneira de realizá-los. Passaram a ser criados programas e projetos referentes a setores específicos, com maior descentralização administrativa, juntamente com grandes projetos de integração nacional.

Foram feitas também algumas modificações importantes no que tange à posição do Estado em relação ao tipo de desenvolvimento desejado para a região amazônica. No segundo Plano, está claramente evidenciada a posição privilegiada que é dada ao capital privado, nacional ou estrangeiro. Enquanto o Plano de 1953 propõe uma associação entre o capital estatal e o privado (sem sequer mencionar o capital estrangeiro), em 1966 vemos que o Estado pretende, fundamentalmente, preparar o terreno para o estabelecimento do capital privado, restringindo-se aos investimentos de infraestrutura, pesquisa e planejamento, que requerem um montante de capital bem maior e com retorno a prazos mais longos.

Além disso, o segundo Plano pretende uma maior racionalidade na exploração dos recursos regionais visando, principalmente, à autossustentação da população já fixada e dos contingentes populacionais que ali venham a estabelecer-se. Desestimula a produção extrativa, preferindo que esta seja substituída, sempre que possível, por atividades mais rentáveis; incentiva o desenvolvimento da agricultura, pecuária e piscicultura como fontes básicas de sustento da população e propõe a seleção de áreas mais propícias ao desenvolvimento, onde se concentrariam os recursos disponíveis, criando pólos de desenvolvimento regional. 
No que se refere à situação social, enquanto o Plano de 1953, provavelmente devido à política populista do então presidente Getúlio Vargas, fala de “... regeneração física e social das populações da região, pela alimentação, a assistência à saúde, o saneamento, a educação e o ensino..." (art. $7^{\circ}, \mathrm{h}$ ), o de 1966, expressando-se de maneira menos paternalista (mas também com muito menor ênfase), apresenta como seu objetivo mais geral o "... desenvolvimento autossustentado da economia e o bem-estar-social da região amazônica, de forma harmônica e integrada na economia nacional" (art. $3^{\circ}$, Lei $n^{\circ} .5 .173$ ).

Outra diferença importante é que, embora ambos se refiram ao estabelecimento de uma política imigratória para a região, com a formação de núcleos estáveis, o segundo se refere explicitamente à fixação de população nas zonas fronteiriças.

A definição de políticas específicas e de sua instrumentação ficou a cargo de diversos órgãos, cuja análise sumária apresentamos a seguir.

\section{A Superintendência do Desenvolvimento da Amazônia (SUDAM)}

A mesma lei que introduziu estas modificações no Plano de Desenvolvimento da Amazônia extinguiu a SPVEA e substituiu-a pela SUDAM, Superintendência do Desenvolvimento da Amazônia (art. $9^{\circ}$ da Lei $n^{\circ}$. 5.173, de 27/10/66).

A SUDAM tem como função coordenar a ação federal na Amazônia, sendo a principal encarregada da elaboração e execução do Plano de Valorização, diretamente ou mediante convênios com entidades públicas ou privadas, utilizando como agente financeiro o Banco da Amazônia, S. A. (BASA).

Tem como atribuições específicas (art. 10):

- avaliar e rever anualmente o Plano;

- coordenar e supervisionar (e mesmo elaborar e executar) os programas e planos de outros órgãos federais que estejam atuando na Amazônia, prestando assistência técnica aos projetos considerados prioritários para o desenvolvimento da região;
- fiscalizar o emprego das verbas destinadas ao Plano de Valorização;

- decidir sobre a distribuição dos recursos provenientes dos incentivos fiscais entre os diversos projetos privados propostos para a região, dando preferência aos que se dediquem à industrialização de matéria-prima regional; fazer sugestões quanto à criação, modificação ou extinção de órgãos e entidades que trabalhem na região amazônica;

- promover e divulgar estudos e pesquisas que permitam um maior conhecimento das potencialidades regionais.

Inicialmente, para o cumprimento destas funções, a SUDAM contaria com:

- no mínimo $2 \%$ da renda tributária da União, dos recursos a que se refere o art. 199 da Constituição Federal;

- 3\% da renda tributária dos Estados, Territórios e Municípios da Amazônia, previstos no parágrafo único do art. 199 da Constituição Federal.

Além disto, a SUDAM pode contar com dotações orçamentárias e créditos adicionais; com o produto de operações de crédito e de juros de depósitos bancários, de multas e emolumentos que lhe são devidos; assim como com lucros provenientes de serviços prestados ou de empresas das quais participe; com auxílios, subvenções, contribuições e doações de entidades privadas ou públicas, nacionais e estrangeiras; com sua renda patrimonial e com todas as isenções tributárias gozadas pelos outros órgãos federais (artigos 20 e 38).

A SUDAM tem a possibilidade, também, de contrair empréstimos no país ou no exterior, dando como garantia seus próprios recursos, com total isenção de taxas e impostos federais (art. $23, \S 5^{\circ}$ ).

A SUDAM pode dispor, ainda, dos recursos do FIDAM (Fundo para Investimentos Privados no Desenvolvimento da Amazônia), também criado pela Lei $\mathrm{n}^{\circ}$. 5.173, art. 45, e posteriormente modificado pela Lei $\mathrm{n}^{\circ}$. 5.374. Inicialmente, o Fundo contava com pelo menos $1 \%$ da renda tributária da União, dos recursos a que se refere o art. 199 da Constituição Federal, passando, em 1967, a contar com “dotações plurianuais, nunca inferiores ao 
montante de sua participação no Plano de Valorização Econômica da Amazônia" (alínea "a” do art. 45)

Mas, ainda, este Fundo é formado por recursos provenientes de dotações, doações e subvenções; do produto da colocação das Obrigações da Amazônia, emitidas pelo BASA; dos recursos anuais do Fundo de Fomento à Produção, dos depósitos provenientes da lei de incentivos fiscais em favor dá Amazônia e da receita líquida proveniente das operações efetuadas com seus recursos próprios. Tanto os recursos da SUDAM quanto os do FIDAM são, obrigatoriamente, depositados no Banco da Amazônia S.A. (BASA), inclusive os provenientes dos incentivos fiscais, enquanto não são entregues à iniciativa privada para o financiamento de pesquisas e empreendimentos considerados prioritários para o desenvolvimento da região.

A primeira lei referente às deduções tributárias para investimentos (Lei nº. 5.174, de 27/10/1966) estipulava que:

- todas as pessoas jurídicas poderiam descontar do imposto de renda: $a$ ) até $75 \%$ do valor das obrigações do BASA que adquirissem; $b$ ) até $50 \%$ do valor do imposto devido para investimentos em projetos agrícolas, pecuários, industriais e de serviços básicos, segundo critérios de prioridades determinados pela SUDAM.

Por serviços básicos entendem-se: energia, transporte, educação, comunicação, colonização, turismo e saúde pública. Em 1969 houve uma modificação, referente aos dois últimos setores: os investimentos em turismo passaram a ser regulados pela EMBRATUR (Empresa Brasileira de Turismo, que também trabalha com base em incentivos) e saneamento básico ficou excluído, com possibilidade de investimento privado.

O fato de o capital privado poder investir em serviços básicos não implica em que o governo não aplique mais na área; as inversões provenientes dos incentivos fiscais seriam apenas complementares.

Além disto, todos os empreendimentos considerados de interesse pela SUDAM e localizados na área teriam uma dedução de $50 \%$ do imposto sobre a renda, até ao ano de 1982, inclusive; os empreendimentos que se instalassem até fins de 1971 teriam esta isenção aumentada para 100\%, assim como os que ainda não tivessem começado a funcionar e os que ampliassem suas instalações até 1971. Estes prazos foram posteriormente dilatados para fins de 1974 (Decreto-lei no. 756/69. art. 23).
Também foram concedidos aos investidores isenções de impostos de exportação (para alguns produtos regionais) e de importação (para máquinas e equipamentos que não tenham similares no mercado nacional e que se destinem a projetos considerados prioritários pela SUDAM). O critério de prioridade obedece, basicamente, às seguintes razões: ocupação territorial, aproveitamento de matérias-primas e mão de obra regionais. Tanto que, embora o investidor possa contar somente com um, terço dos incentivos para o total do investimento, fica a cargo da SUDAM determinar esta proporção, conforme o projeto esteja mais próximo das prioridades acima definidas. Também quanto aos prazos de isenções os investimentos considerados prioritários levam vantagens: podem ficar sem pagar o imposto sobre a renda por até quinze anos a contar da data de funcionamento da empresa.

Mas o fato de um projeto se situar dentro desta faixa de prioridades não é suficiente para sua aprovação pela SUDAM. Podemos citar, a título de exemplo, alguns dos requisitos necessários:

- que o empreendimento tenha sua sede localizada na região amazônica;

- que apresente custos competitivos e rentabilidade comprovada;

- que haja mercado regional ou extrarregional para os bens a serem produzidos.

A aprovação dos projetos privados está a cargo, atualmente, do Conselho Deliberativo da SUDAM - CONDEL -, que tem ainda as seguintes atribuições: aprovar normas, fixar prioridades e modificar critérios referentes à aprovação dos empreendimentos privados; decidir sobre as isenções de impostos; sugerir ao Conselho Monetário Nacional quais produtos regionais devem estar isentos do imposto de exportação; decidir sobre a concessão de isenção de imposto de importação aos bens de capital que se destinem à região; aprovar convênios, contratos e acordos firmados pela SUDAM; avaliar e aprovar seu orçamento-programa; aprovar as operações de crédito, no país e no exterior; definir os setores mais importantes no que se refere aos investimentos em infraestrutura, tais como energia, transporte, comunicações, colonização, turismo, educação e saúde pública; opinar sobre e acompanhar a execução do Plano de Valorização Econômica. 
Este conselho deliberativo é formado pelo superintendente, por um representante de cada ministério, e ainda um representante do Estado-maior das Forças Armadas, do Banco Nacional de Desenvolvimento Econômico, do Banco do Brasil, do Conselho Nacional de Pesquisas, o presidente do BASA e o superintendente da Zona Franca de Manaus. E interessante notar que, até 1968, quando o CONDEL se denominava Conselho de Desenvolvimento da Amazônia - CONDAM - e tinha praticamente as mesmas atribuições de hoje em dia, fazia parte dele um representante dos empregadores: um dos empregados do setor rural, um do setor comercial e um do industrial.

\section{O Instituto Nacional de Colonização e Reforma Agrária (INCRA)}

As origens do INCRA remontam a 1934, quando a questão referente à colonização no Brasil passou a ser tratada, definitivamente, pelo Ministério da Agricultura. Neste ano foi criado o Serviço de Irrigação, Reflorestamento e Colonização ${ }^{103}$ e desde então os problemas de colonização oficial estiveram sempre sob a responsabilidade de um órgão diretamente vinculado a este ministério.

Em 1938 surgiu a Divisão de Terras e Colonização - DTC - que foi o resultado prático de preocupações a nível político com a fixação do homem à terra $\mathrm{e} o$ abrandamento das tensões sociais com a ampliação da fronteira agrícola, tendo sido a primeira tentativa de realização de um trabalho sistemático em colonização. Tinha como objetivo principal a fundação de núcleos populacionais estáveis, com distribuição de terras a trabalhadores rurais brasileiros. ${ }^{104}$ A DTC deixou, em seus dezesseis anos de trabalho, vários núcleos de colonização, sendo os mais importantes as Colônias Agrícolas Nacionais, em vários Estados. ${ }^{105}$

\footnotetext{
${ }^{103}$ Decreto $n^{\circ} .24 .467$, de 26 de junho de 1934.

${ }^{104}$ Decreto-lei no . 3.059, de 14 de fevereiro de 1941, referente à criação de Colônias Agrícolas Nacionais, in TAVARES, Vânia Porto e outros, Colonização Dirigida no Brasil, op. cit., p. 32.

${ }^{105}$ Dentre os núcleos estabelecidos pela Divisão de Terras e Colonização destacaram-se (apud fonte da nota anterior):

No Estado do Rio de Janeiro: Tinguá, Macaé, Duque de Caxias, Sapucaia, Santa Cruz

Na Bahia: Ituberá, Jaguaquara, Una e Porto Seguro

Em Mato Grosso: Dourados

Em Goiás: Ceres
}

A Divisão de Terras e Colonização foi substituída, em 1954, pelo Instituto Nacional de Imigração e Colonização - INIC $-{ }^{106}$ que ficou encarregado da elaboração e execução de um programa de colonização de âmbito nacional, com a formação de pequenas propriedades agrícolas. Uma diferença importante entre a política do DTC e do INIC é que o primeiro órgão deveria restringir suas atividades aos cidadãos brasileiros, enquanto que o segundo cuidaria também da fixação de imigrantes. O INIC durou oito anos e como resultado maior de seu trabalho deixou implantados alguns núcleos coloniais no nordeste (Piauí, Ceará, Pernambuco, Alagoas e Bahia). ${ }^{107}$

Em 1962 houve outra mudança administrativa; foi criada a SUPRA Superintendência da Política Agrária - ${ }^{108}$ que reuniu o Instituto Nacional de Imigração e colonização, o Serviço Social Rural e o Estabelecimento Rural dos Tapajós. Suas realizações foram tão pequenas quanto sua duração: extinta em 1964, a SUPRA limitou-se a fazer alguns estudos sobre o problema de colonização e a entregar alguns títulos de posse definitiva da terra em núcleos já estabelecidos. ${ }^{109}$

Com a promulgação do Estatuto da Terra ${ }^{110}$, foram criados o Instituto Nacional de Desenvolvimento Agrário e o Instituto Brasileiro de Reforma Agrária. O IBRA ficou encarregado dos Estados do Rio de Janeiro, Ceará,

Em Minas Gerais: Jaíba

No Maranhão: Barra do Corda

No Pará: Monte Alegre

No Amazonas: Bela Vista

No Paraná: General Osório

No Piauí: David Caldas

${ }^{106}$ Lei no ${ }^{\circ} .2 .163$, de 5 de janeiro de 1954

${ }^{107}$ Foram os seguintes os núcleos implantados pelo INIC (apud fonte da nota 103):

No Estado do Rio Grande do norte: Pium, D. Marcolino Dantas

Em Pernambuco: Rio Bonito

No Ceará: Pio XII

No Rio de Janeiro: Santa Alice

Na Bahia: Jeremoaba, Queimadas e Andaraí

No Pará: Guamá

No Piauí: Gurguéia

Em Goiás: Bernardo Sayão

${ }^{108}$ Lei delegada $n^{\circ}$. 11, de 11 de outubro de 1962.

109 A SUPRA chegou a implantar apenas dois núcleos: o Alexandre de Gusmão, no Distrito Federal, e o de Andradas.

${ }^{110}$ Lei n ${ }^{\circ} .4 .504$, de 30 de novembro de 1964. 
Rio Grande do Sul e Distrito Federal; partes de Minas Gerais, São Paulo, Goiás, Pernambuco e Paraíba, áreas declaradas prioritárias para a reforma agrária. O IBRA tentou reformular as políticas até então adotadas, mas somente em núcleos já estabelecidos nessas regiões. Chegou a iniciar alguns projetos, enfrentando grandes dificuldades quanto a recursos e apoio político. O INDA ficou encarregado das colônias localizadas fora das áreas prioritárias, o que incluía a região amazônica. Em 1968, com nova reforma, todos os núcleos de colonização ficaram a cargo do IBRA. Em 1969, sob recomendação da FAO (em missão no Brasil) e do GERA (Grupo Interministerial de Trabalho sobre a Reforma Agrária), começou a ser estudada a fusão dos dois órgãos, que se concretizou em 1970, com a criação do Instituto Nacional de Colonização e Reforma Agrária. ${ }^{111}$

O INCRA nasceu, assim, tanto de uma necessidade de simplificação administrativa quanto de uma reformulação de políticas de colonização no Brasil. Por esta época, o então Presidente Emilio G. Médici fez uma viagem ao nordeste, onde pôde constatar pessoalmente os problemas gerados pela forte seca de 1970. Como solução para a diminuição das tensões sociais existentes na área, decidiu-se a abertura de estradas na Amazônia, com o aproveitamento da mão de obra nordestina e sua subsequente fixação ao longo destas rodovias. Isto está claramente explícito nas declarações de José Francisco de Moura Cavalcanti, então presidente do INCRA: "Damos uma ênfase maior à colonização, principalmente da Transamazônica, porque não compreendemos como num mesmo país possa constituir problema de inquietação o excedente demográfico de determinadas áreas e o vazio de outras"112.

O INCRA tem como objetivos principais a realização da reforma agrária no Brasil, a promoção da colonização particular e a execução da colonização oficial e do desenvolvimento no campo, através do cooperativismo e da eletrificação rural. Para tanto, metodologicamente, deve proceder a uma divisão do país em regiões homogêneas, classificandoas segundo características sócio-econômicas, sendo a estrutura fundiária uma das variáveis de maior peso nesta classificação. Isto permitirá a definição de políticas agrícolas adequadas a cada região, assim como a seleção de áreas a serem consideradas prioritárias, portanto passíveis de

\footnotetext{
${ }^{111}$ Decreto-lei no ${ }^{\circ} .1 .110$, de 9 de julho de 1970.

${ }_{112}$ O Estado de S. Paulo, 25 de julho de 1970.

desapropriação com fins de reforma agrária, conforme se julgue necessário. O INCRA mantém um serviço de Cadastramento de Imóveis rurais, de arrendatários, de parceiros e de terras públicas, alimentado através de levantamentos periódicos, inquéritos e pesquisas de documentação e que fornece os dados indispensáveis à caracterização das propriedades, tais como forma de ocupação e exploração.

Em abril de 1971 foi possibilitada à iniciativa privada a implantação de projetos de colonização em áreas consideradas prioritárias para a reforma agrária e nas terras devolutas da União na Amazônia, mas somente para projetos aprovados pelo INCRA. A participação do capital privado deve concentrar-se, basicamente, no setor de infraestrutura necessária à formação dos núcleos. Quando o projeto se localiza em terras do INCRA, este conserva o direito de propriedade, transferindo-o diretamente ao colono estabelecido, mas garantindo ao empresário o retorno do investimento com base no contrato previamente aprovado. O INCRA se reserva, ainda, o direito de definir as obrigações de ambas as partes, colonos e colonizadores.

Em dezembro de 1972 o governo decide abrir ao capital privado o desenvolvimento de projetos agropecuários de pequeno porte na Amazônia. O INCRA abre à concorrência pública, inicialmente, 500 mil hectares em Rondônia e 250 mil em Marabá (Estado do Pará), divididos em lotes de até 3 mil hectares cada um. Pelo tamanho dos lotes e pelas exigências técnicas aos licitantes pode-se perceber que o objetivo seria atrair, fundamentalmente, os pequenos e médios empresários rurais. Além disso, o INCRA estabelece um tratamento preferencial às pessoas já fixadas nas terras em questão, exigindo dos eventuais compradores um mínimo de conhecimento prévio e de experiência sobre atividades agropecuárias. ${ }^{113}$ Há a obrigatoriedade de

${ }^{113}$ Portaria do INCRA, de 13 de dezembro de 1972:

1.3 - Documentação relativa à capacidade técnica dos licitantes:

- comprovação de conhecimentos de agricultura mediante atestados fornecidos por entidades de classe, associação profissional, cooperativa de produtores rurais, casa de lavoura, etc. ou por profissionais de entidade oficial e/ou de habilitação profissional em agricultura (agrônomos, veterinários, técnicos agrícolas).

- comprovação de operação de financiamentos agropecuários, obtidos junto a entidades de crédito rural, se possuir: prova de propriedade de equipamentos agrícolas (tratores, máquinas, implementos etc.) e/ou matrizes de animais de produção, se for o caso.

- prova de que é ou foi proprietário rural, arrendatário, de propriedade agrícola, gerente, administrador ou sócio de empreendimentos agropecuários ou filho de agricultor ou criador. 
apresentação de um anteprojeto definindo como será efetuado o aproveitamento da terra, o montante do investimento previsto, com estimativas dos custos de produção, das perdas eventuais e das possibilidades de comercialização, assim como do número de empregos diretamente gerados e condições sociais dos assalariados (moradia, educação, saneamento básico, assistência médica etc.). Estes projetos devem ser implantados no prazo máximo de cinco anos, sob pena de perda da propriedade. Fica a cargo do INCRA o controle de execução destes projetos.

Além do INCRA e da SUDAM - esta última apoiando-se financeiramente no Banco da Amazônia S.A., que opera os recursos do Fundo para Investimentos Privados no Desenvolvimento da Amazônia (FIDAM) - existem vários outros órgãos federais, empresas públicas e programas especiais que atuam na Amazônia. Para que se tenha uma ideia de alguns dos principais programas, passamos a enumerar, em continuação, as atribuições e as áreas de atuação deles.

\section{Plano de Integração Nacional (PIN)}

O PIN, criado pelo Decreto-lei no. 1.106 , de junho de 1970 , tem como finalidade específica "financiar o plano de obras de infraestrutura nas regiões compreendidas nas áreas de atuação da SUDENE e da SUDAM e promover sua mais rápida integração à economia nacional".

Dotação de recursos no valor de Cr\$ 2 bilhões (de 1970), provenientes de:

1. recursos orçamentários, previstos nos orçamentos anuais e plurianuais;

2. recursos provenientes de incentivos fiscais (de 1971 a 1974, 30\% do total deduzido do imposto de renda serão creditados ao PIN);

3. contribuições e doações de empresas públicas e privadas;

4. empréstimos de instituições financeiras nacionais e internacionais;

5. recursos de outras fontes.

A primeira etapa do PIN compreende a construção da Transamazônica e da Cuiabá-Santarém e o Plano de Irrigação do Nordeste. A colonização e exploração econômica das áreas desapropriadas ao longo destas rodovias serão efetuadas com recursos do PIN.
A divisão de tarefas consta no Decreto $n^{\circ}$. 67.113, de 2/8/1970: o Ministério dos Transportes fica com as rodovias e portos fluviais; o Ministério da Agricultura ocupa-se da colonização e reforma agrária; o Ministério do Interior cuida do Plano de Irrigação e o Ministério de Minas e Energia está encarregado do levantamento topográfico.

\section{Superintendência da Zona Franca de Manaus (SUFRAMA)}

A SUFRAMA (Decreto-lei no. 288, de 28 de fevereiro de 1967), o órgão encarregado de administrar a Zona Franca de Manaus, é uma autarquia vinculada ao Ministério do Interior, sem qualquer relação direta com a. SUDAM, ainda que esteja incluída em seu plano diretor.

A SUFRAMA tem como funções elaborar o plano Diretor da área (10000 km² à margem esquerda dos rios Negro e Amazonas) e promover seu desenvolvimento diretamente ou mediante convênio com outras entidades públicas ou privadas. O objetivo principal é integrar a Amazônia ocidental ao resto do país, mediante a criação de um centro industrial e agropecuário. Para tanto, estabeleceram-se nesta área condições fiscais especiais (isenção de imposto sobre produtos industrializados - IPI -; imposto de circulação de mercadorias - ICM -; imposto de importação e exportação), procurando facilitar o comércio tanto com o exterior quanto com o sul do país.

O distrito agropecuário tem como função abastecer Manaus, servindo também como uma área de estudo de viabilidade econômica da Amazônia.

\section{Companhia de Pesquisa de Recursos Minerais (CPRM)}

(Decreto-lei n ${ }^{\circ} .764$, de 15 de agosto de 1969).

\section{Objetivos:}

1. estimular o descobrimento e aproveitamento dos recursos minerais e hídricos;

2. orientar, incentivar e cooperar com a iniciativa privada na pesquisa e em estudos destinados ao aproveitamento destes recursos;

3. suplementar a iniciativa privada em ação estritamente limitada ao campo de pesquisa; 
4. dar apoio administrativo e técnico aos órgãos de administração direta do Ministério de Minas e Energia.

Portanto, a CPRM fica somente com a pesquisa mineral (maior dose de risco, menor atividade para o capital privado); a descoberta de um corpo mineral explorável leva em geral à sua licitação pública, para exploração pelo capital privado.

O Departamento Nacional de Produção Mineral (DNPM) ${ }^{114}$ possui três agências na Amazônia (Belém, Manaus e Porto Velho), atuando em três ramos de atividade:

1. como empresa de serviços executando sete projetos para o DNPM e três para a SUDAM: para o DNPM trata-se de sete pesquisas geológicoeconômicas que cobrirão cerca de $1.788 .000 \mathrm{~km}^{2}$; para a SUDAM tratase igualmente de avaliações geológico-econômicas em três áreas da Amazônia: zona Belém e Bragantina (PA), zona Xingu-Amazônia e zona da Bacia Amazônica.

2. como empresa de mineração, desenvolvendo oito projetos próprios: trata-se de pesquisar a ocorrência de minerais (bauxita, molibdênio, caulim, prata, cobre, chumbo, zinco e outros não ferrosos); para tanto o DNPM dispõe de Cr\$ 9 milhões a serem empregados em dois anos (1972/74).

Como empresa de financiamento, concedendo recursos para a realização de três projetos de pesquisa mineral: à Mineração Angelim S.A. (50 mil ha; município de Novo Aripuanã, AM), à Mineração Araçazeiro Ltda. (30 mil ha, município de Porto Velho, RO) e à Progresso de Rondônia Mineração Ltda. (20 mil ha, município de Guarajará-Mirim), todos destinados à pesquisa-exploração de cassiterita.

\section{Comitê Coordenador dos Estudos Energéticos da Amazônia}

Órgão do Ministério das Minas e Energia (Decreto no . 63.952, de 31 de dezembro de 1968, com representantes dos Ministérios do Interior e do Planejamento). Tem como funções: supervisionar os estudos referentes ao aproveitamento do potencial energético da Amazônia; preparar os

114 Perspectivas do Setor Mineral - Atuação do CRPM, XXVI Congresso Brasileiro de Geologia, Belém, outubro, 1972. orçamentos e autorizar despesas; deliberar sobre as soluções técnicas possíveis; propor ao Ministro as providências necessárias à execução de seus serviços; prestar contas às entidades financiadoras.

As Centrais Elétricas Brasileiras S.A. (ELETROBRÁS) ficam como agente executivo do Comitê. Os estudos programados por este Comitê serão financiados pela FINEP S.A. (Financiadora de Estudos de Projetos S.A.) do Ministério do Planejamento e Coordenação Geral. No Relatório de 1971 constam os resultados de alguns estudos que indicam um potencial superior a 5 milhões de quilowatts:

Os trabalhos realizados compreenderam o estudo dos mercados de energia elétrica a serem supridos em 1985 e o inventário das possibilidades de aproveitamento hidrelétrico para esse suprimento, abrangendo os seguintes pólos de desenvolvimento e as respectivas áreas de influência:

Belém, Santarém e Monte Alegre (Pará)

Macapá (Amapá)

Manaus e Tefé (Amazonas)

Boa Vista (Roraima)

Porto Velho (Rondônia)

Rio Branco (Acre)

Nos trabalhos de inventário foram examinados 26 rios da Amazônia, sendo que em 11 se localizaram locais de aproveitamento. Estes trabalhos foram custeados pela ELETROBRÁS em montante superior a $\mathrm{Cr} \$ 10$ milhões. ${ }^{11}$

\section{Projeto Radar da Amazônia (RADAM)}

O Projeto RADAM foi criado em 1970 pelo Departamento Naciona de Produção Mineral do Ministério de Minas e Energia. É incorporado ao PIN. Tem como objetivos levantar os elementos básicos necessários a um planejamento racional do aproveitamento integrado dos recursos naturais da região amazônica.

Possui atualmente sete setores: geologia (mapeamento geológico); vegetação (mapeamento fitecológico); solos (mapeamento ao nível exploratório de solos e sua interpretação para mapa de aptidão agrícola);

${ }^{115}$ Relatório do Ministério de Minas e Energia, 1971, p. 58. 
geomorfologia; cartografia (mapeamento topográfico); e o de uso potencial da terra (mapeamento da avaliação média da capacidade natural da terra).

Participam do Projeto RADAM os seguintes Ministérios e Governos Estaduais: Ministério da Agricultura (INCRA, IPEAN, INPA), Ministério do Interior (SUDENE, SUDAM, FUNAI), Ministério da Educação (Universidade de Brasília e do Rio Grande do Sul), Ministério da Saúde (Instituto Oswaldo Cruz), Ministério do Exército (DSG), Ministério dos Transportes (OPEMA), Ministério do Planejamento (FIBGE), Governo do Estado do Pará (IDESP), Governo do Estado do Maranhão (SUDEMA) e Governo do Estado do Piam (Secretaria do Planejamento).

\section{A Autoimagem da Ação Governamental - SUDAM e INCRA}

Convém agora indicar algumas das principais políticas de ocupação do solo e da colonização que têm sido postas, se não em execução, pelo menos na ordem do dia dos expedientes governamentais e dos meios de comunicação de massa. Nos capítulos seguintes faremos uma avaliação do avanço efetivo destas políticas.

Limitar-nos-emos a alguns aspectos das políticas instrumentadas pela SUDAM e pelo INCRA para dar uma ideia dos métodos de abordagem usados para lidar, com o desafio da ocupação da Amazônia.

\section{A) Alguns aspectos dos planos de desenvolvimento da SUDAM (1972/74)}

Todos os órgãos de planejamento regional, no Brasil, encontram-se subordinados ao Ministério do Interior (MINTER), que propõe as diretrizes gerais a serem seguidas pelos diversos planos de desenvolvimento. $O$ "Esquema de Trabalho para Elaboração dos Planos Regionais de Desenvolvimento" fornece, como referência básica, uma tabela de indicadores nacionais, em relação à qual devem ser calculados os desvios apresentados por cada Estado ou região. São eles:

1. Recursos naturais: aerofotogrametria, cartografia, geologia, pedologia, meteorologia, fluviometria.

2. Infraestrutura econômica: energia elétrica, comunicações, transportes,

3. Infraestrutura social: educação, saúde, cultura, saneamento básico (urbano).
4. Setores produtivos: silvicultura, agricultura, pecuária, indústria de transformação, serviços.

5. Administração e serviços públicos.

A meta principal seria a homogeneização de todas as regiões do Brasil, procurando cobrir as diferenças apresentadas por cada setor em relação ao mínimo estabelecido pelo governo.

E claro que aí devem ser consideradas certas peculiaridades regionais, e isto tanto no que se refere à metodologia a ser empregada quanto no tocante à importância maior ou menor (ou mesmo à não pertinência) de alguns indicadores dentre os fornecidos pelo Esquema de Trabalho do Ministério do Interior.

No caso da Amazônia, a SUDAM adotou o município como unidade territorial básica, em vez das microrregiões homogêneas, ou áreas de aproximadamente 25.000 quilômetros quadrados (como o sugerido pelo MINTER), dada a grande heterogeneidade da região: zonas densamente povoadas, onde há uma relativa concentração de população e recursos, ao lado de espaços praticamente inabitados. A utilização de uma unidade espacial maior, neste caso, forçosamente acarretaria a diluição da informação dando uma ideia de homogeneidade irreal

Quanto aos indicadores, a SUDAM suprimiu uns (silvicultura, produção e consumo de batatas, por exemplo); modificou outros (consumo de energia elétrica calculado pela população urbana, já que não há eletrificação rural por conta do Estado); e ainda criou alguns (inventários florestais, produção e consumo de aipim etc.).

Por falta de dados estatísticos mais recentes, o Plano Regional de 1972/74 para a Amazônia foi inteiramente baseado em dados de 1968, o que significa que, ainda que se possa ter com isto uma "ordem de grandeza" regional, existe uma grande diferença em relação à realidade de 1970.

Mesmo assim, com base nestes dados, foram localizados os setores em que a região amazônica se distancia mais das médias brasileiras consideradas como padrão. O mais importante são os déficits existentes no setor de infraestrutura social, principalmente no tocante à situação educacional.

Como se pode perceber, a SUDAM se propõe a atuar em praticamente todos os setores necessários ao desenvolvimento equilibrado 
da região. Pretendemos aqui analisar mais de perto suas propostas de atuação em dois setores da infraestrutura social (educação e saúde), que consideramos os mais relevantes para o estudo da política demográfica e suas implicações no plano social, excluindo os aspectos econômicos e de infraestrutura, já analisados na primeira parte deste estudo.

Educação - Utilizando dados referentes ao período de 1960/70, os técnicos da SUDAM procuraram definir quais seriam os principais problemas educacionais da Amazônia. Com base nestes dados, e obedecendo a diretrizes estabelecidas pelo Ministério de Educação e Cultura, através do Plano Nacional de Educação, foram elaborados cinco projetos, visando atenuar as principais falhas do sistema de ensino.

- Projeto Operação-Escola: Tem como objetivo a ampliação da rede escolar, pois o número de escolas existente não é suficiente para absorver toda a população na faixa dos 7 aos 14 anos, cuja obrigatoriedade de frequência à escola é determinada pela Constituição.

- Projeto Capacitação e Treinamento: Visa melhorar o nível do corpo docente, principalmente para as áreas rurais, onde predomina o magistério leigo (em Roraima, por exemplo, $71 \%$ ).

- Projeto Formação de Mão de obra: Visa a melhor formação é qualificação da mão de obra para atendimento da demanda do mercado regional, considerando-se aí a importância do trabalho qualificado no processo de colonização e ocupação econômica da região.

Saúde - Apesar da precariedade dos dados estatísticos disponíveis, a SUDAM procurou definir os principais problemas do setor na Amazônia:

- alta incidência de doenças transmissíveis, principalmente lepra, malária e tuberculose;

- subnutrição e alimentação deficiente de grande maioria da população;

- alta taxa de mortalidade na faixa mais jovem da população, indicando a existência de doenças infecciosas;

- unidades hospitalares muito mal equipadas e em número insuficiente para atender às necessidades da região.

Foi feita uma comparação entre os indicadores nacionais de saúde e a situação na região, onde se verifica que em apenas um dos indicadores -
Unidade Hospitalar Completa - a Amazônia apresenta um superávit. Em relação a todos os outros se pode constatar um déficit para o total da região, ainda que existam diferenças marcantes entre os Estados e Territórios que a compõem. Em geral, somente nas Capitais é que a situação do setor saúde se apresenta acima das médias nacionais. Por exemplo:

- leitos: há um déficit de $40 \%$ na região, ou seja, não chega a haver um leito para cada 1000 habitantes (apenas 0,6), embora exista mais do que este mínimo em Rio Branco (30\%), Manaus (20\%), Belém (30\%)-e Boa Vista $(80 \%)$;

- pessoal de serviço de saúde: o mínimo estabelecido nos indicadores nacionais é de 10 por 10.000 habitantes (pessoal de nível superior); a região apresenta 4,7, ou seja, um déficit de 53\%. Somente em Belém se encontram $45 \%$ a mais. Quanto ao pessoal de nível médio (mínimo estabelecido de 5/10.000 habitantes), há apenas um para cada 10.000 habitantes, havendo Estados em que não há nenhum (Acre) ou em que a falta é da ordem de 90\% (Amazonas).

Pelo que se pode concluir do Plano Regional de Desenvolvimento, a SUDAM não destinou nenhuma parcela de sua verba ao setor saúde, ainda que se proponha a coordenar a atuação de outros órgãos na região. Segundo o Plano, o problema principal seria o da falta de entrosamento existente entre, primeiro, os três níveis de governo (federal, estadual e municipal); e, segundo, entre os órgãos existentes num mesmo nível (entre as Secretarias de Saúde e de Educação, por exemplo, no tocante à Educação Sanitária).

Além destes, a SUDAM é de opinião que se deveria dar mais atenção à prevenção e controle das doenças do que à recuperação, como se faz atualmente. Com vistas à eliminação destes problemas, a SUDAM define como diretrizes básicas de sua atuação:

- a reestruturação das secretarias e divisões de saúde dos Estados e Territórios;

- a realização de pesquisas de interesse médico-sanitário;

- a criação de um processo de planejamento permanente, onde se procuraria racionalizar ao máximo a distribuição dos recursos disponíveis no setor, procurando-se integrar a atuação de todos os órgãos, locais e regionais. 


\section{B) As diretrizes do INCRA}

O INCRA criou um método de trabalho a ser empregado em todos os projetos de colonização no Brasil, no qual são definidos os setores em que o órgão deve atuar, o que deve ser realizado em cada um deles e quais os limites de sua responsabilidade. Esta metodologia é a diretriz básica no que se refere à colonização oficial a nível de propriedade familiar, e é a que vem sendo utilizada em todos os projetos implantados a partir de 1971.

Foram definidas, inicialmente, três unidades básicas de trabalho: Organização Fundiária, Organização Agrária e Promoção Agrária, divididas em duas subunidades cada uma, que correspondem a 12 programas abrangendo os setores considerados fundamentais à instalação e funcionamento de um núcleo colonial.

O método resume-se, basicamente, no que segue.

\section{Organização Fundiária}

Esta é a primeira unidade de trabalho, encarregada de situar espacialmente o núcleo, delimitar o loteamento, definir as áreas destinadas aos lotes e aos serviços básicos, fazer o levantamento da situação jurídica das terras em questão e proceder à alienação. Subdivide-se em Regularização Fundiária (que trata da parte jurídica) e Topografia (da parte física).

Esta unidade coordena dois programas: o de Distribuição de Terras e o de Organização Territorial, ambos a serem realizados até à conclusão do projeto sob total responsabilidade do INCRA. O programa de Distribuição de Terras engloba todas as medidas necessárias à transferência da posse, tais como pagamento de indenização aos antigos proprietários, legalização dos títulos, realização de contratos com os novos parceleiros (proprietários de pequenas parcelas de terra), só findando quando $2 / 3$ dos lotes estiverem efetivamente ocupados há 5 anos. O de Organização Territorial encarregase da implantação do plano de loteamento, determinando as áreas destinadas às instalações dos programas de saúde, educação, administração, comercialização, beneficiamento e industrialização. Fica a seu cargo ainda a elaboração de plantas topográficas referentes a cada lote, que devem ser entregues aos parceleiros.

\section{Organização Agrária}

Esta segunda unidade subdivide-se em Organização Social e Infraestrutura Social. A primeira trata da mobilização e organização das pessoas estabelecidas na área e do setor administrativo do projeto, bem como das relações entre estas duas partes. Tem a seu cargo dois programas, a serem totalmente executados pelo INCRA: o de Administração do Projeto e o de Assentamento. É através do programa de "Assentamento que os futuros colonos são selecionados e treinados a organizar-se em Unidades Agrárias de Produção - UATP. Estas unidades visam criar um espírito de colaboração entre os parceleiros e, ao mesmo tempo, torná-los capazes de gradualmente assumir todas as decisões referentes ao bom funcionamento do núcleo. Uma UATP é formada pelo mínimo de 6 e um máximo de 12 parceleiros, e o critério de agrupamento é o de vizinhança. Há, em cada unidade, uma divisão de tarefas em que cada integrante se ocupa de um setor (comunicação, educação, saúde, controle de ocupação, infraestrutura, crédito, serviços técnicos, agricultura, comercialização e comissão de representantes). São promovidas reuniões periódicas para a discussão dos problemas que surgem e as decisões devem ser tomadas por todos os colonos em conjunto. A Equipe Técnica do Projeto pode intervir, se achar necessário, mas somente com a presença de todos os membros da unidade.

Estas unidades têm como função, portanto, fazer com que os parceleiros atinjam certo grau de auto-suficiência no equacionamento e solução de seus próprios problemas ainda que quem os resolva mesmo, em última análise, seja sempre a Comissão Técnica encarregada do Projeto. Isto se pode perceber ao se analisarem mais detidamente as atribuições de cada encarregado de setor, dentro da unidade. Por exemplo, o encarregado de Saúde deve:

1. informar a Equipe Técnica sobre as necessidades de medicamentos para os primeiros socorros;

2. atender os casos de curativos e primeiros socorros;

3. comunicar à Equipe Técnica ou ao enfermeiro os casos de doenças, acidentes ou epidemias;

4. incentivar a unidade na vacinação das crianças e na prevenção e tratamento das doenças transmissíveis. 
O encarregado de Crédito, por sua vez, deve:

1. fazer o levantamento das necessidades de crédito e encaminhá-lo à Equipe Técnica;

2. colaborar com a Equipe Técnica na elaboração do plano de exploração da parcela;

3. fiscalizar a correta aplicação do crédito recebido, comunicando à Equipe Técnica as irregularidades observadas;

4. providenciar as assinaturas dos recibos de crédito;

5. colaborar na fiscalização do crédito bancário, de acordo com normas a serem expedidas.

Além disso, há em cada unidade uma pessoa encarregada da Comunicação, ou seja, de fazer a integração entre cada grupo e a Equipe Técnica. O objetivo, a longo prazo, é a formação de uma Empresa Cooperativa, constituída de representantes de várias unidades, que promova a emancipação do Projeto e, consequentemente, reduza os custos administrativos.

A segunda subunidade, a de Infraestrutura Social, se encarrega da promoção de três programas, ou seja, o INCRA apenas coordena as atividades dos programas de Educação, Saúde e Previdência Social e de Habitação Rural, sendo que as realizações nesses setores ficam a cargo de outros órgãos, em geral os ministérios correspondentes.

Os objetivos são os seguintes, em cada programa:

- Educação: Montar e equipar uma rede de ensino suficiente para o atendimento de todas as crianças em idade escolar, promovendo também a alfabetização de adultos; fazer com que a própria comunidade se encarregue da manutenção destas escolas, através do treinamento do encarregado do setor em cada UATP, e ainda verificar se o ensino se adequa aos objetivos do Projeto.

- Saúde e Previdência Social: Instalação de um ambulatório e integração dos parceleiros ao sistema de previdência social oficial, fazendo com que eles passem gradativamente a ocupar-se dos problemas do setor.

- Habitação Rural: Elaboração do plano de habitação, com a instalação dos novos habitantes em moradias adequadas. Foi elaborada uma forma de organização urbano-rural básica a ser utilizada em todos os projetos de colonização oficial e que conta com três tipos de núcleos urbanos interdependentes: Agrovila - composta em média de 50 famílias, conta com uma escola primária, um pequeno posto de atendimento de saúde e comércio reduzido. Circundando a agrovila, a distâncias que variam de $500 \mathrm{~m}$ a 5 km, estão os lotes rurais, de 100 hectares cada um. Agrópolis polariza, em média, 20 agrovilas; conta com uma cooperativa, um posto de assistência social e de saúde, um de assistência técnica, escola primária, agroindústrias e serviços urbanos de infraestrutura. E, também, o centro administrativo dos órgãos públicos. Deve ser instalado a cada $40 \mathrm{~km}$. Rurópolis - localiza-se no centro do círculo, sendo o ponto de integração entre agrovilas e agrópolis. É o principal dentre os três núcleos urbanos, e é onde devem concentrar-se as atividades industriais e comerciais. Pode tanto originar-se do desenvolvimento posterior de algumas agrovilas, convenientemente localizadas, quanto pelo crescimento de formações urbanas já existentes. Deve surgir, em média, a cada 140 km.

\section{Promoção Agrária}

Esta é a terceira unidade de trabalho, que se subdivide em Uso da Terra e Economia da Terra.

A primeira subunidade, Uso da Terra, controla dois programas, cuja execução total fica a cargo do INCRA. Tem como objetivo geral a organização da produção nas parcelas ou lotes. O primeiro programa Unidades Agrícolas - elabora e implementa um plano de produção adequado à região, determinando o tipo de cultura a ser implantado, fazendo viveiros experimentais e criando um sistema de assessoria técnica aos parceleiros. Depois da primeira safra há uma avaliação da produção, quando é definida a atividade agropecuária a que devem dedicar-se os produtores e, juntamente com as UATPs, é feita a programação futura. O programa dá-se por encerrado quando os parceleiros atingem um nível de renda suficiente para a liquidação total dos vários financiamentos recebidos e quando conseguem administrar toda a produção por conta própria, através das UATPs e suas Empresas Cooperativas.

O segundo programa - de Infraestrutura Física - está estritamente ligado ao programa anterior e ao programa de Organização Territorial. Tem como objetivo a execução direta ou indireta de todas as obras infraestruturais necessárias à produção, tais como irrigação, drenagem, estradas, etc. 
A segunda subunidade, a de Economia da Terra, trata fundamentalmente da distribuição da produção e encarrega-se de promover três programas, sobre os quais o INCRA não tem a responsabilidade de execução. O programa da Empresa Cooperativa visa a ajudar os parceleiros a conseguir administrar autonomamente todo o empreendimento, através de um órgão criado pelos próprios produtores com representantes das várias UATPs. A função do INCRA, neste caso, seria a de assessorá-los na montagem desta. Cooperativa, cuidando de seu registro, instalação e funcionamento definitivo.

O segundo programa desta subunidade é o de Crédito, através do qual deve ser elaborado e implantado um sistema de crédito rural para financiamento e comercialização da produção. Este plano encarrega-se de verificar qual a aplicação que está sendo dada, pelos parceleiros, aos recursos recebidos, zelar pelos pagamentos dos financiamentos e também instruir os produtores sobre o funcionamento do sistema creditício, de tal maneira que a Empresa Cooperativa possa, mais tarde, encarregar-se de todas as atividades do setor.

O terceiro e último programa, o de Comercialização, também tem como objetivo último o controle total do sistema por parte da Empresa Cooperativa. Para tanto são feitos inicialmente um estudo de mercado e a avaliação da produção comercializável, cuidando-se para que haja um bom funcionamento do setor de armazenagem e escoamento. As primeiras vendas são realizadas no programa, passando gradualmente à responsabilidade da seção de comercialização da Cooperativa dos Parceleiros. 